\title{
Influência do cromo no desempenho, na qualidade da carne e no teor de lipídeos no plasma sanguíneo de frangos de corte
}

\section{Luciana Maria Garcia de Souza ${ }^{1}$, Alice Eiko Murakami ${ }^{1}$, Jovanir Inês Müller Fernandes ${ }^{1}$, Rafael Lachinski de Holanda Guerra ${ }^{1}$, Elias Nunes Martins ${ }^{1}$}

1 Universidade Estadual de Maringá - UEM.

RESUMO - Avaliou-se o efeito da suplementação de cromo na dieta sobre o desempenho, o rendimento de carcaça, a qualidade da carne, o teor de colesterol no peito e os parâmetros bioquímicos do sangue de frangos de corte. O delineamento experimental utilizado foi o inteiramente casualizado, com cinco níveis de tripicolinato de cromo $(0,150,300,450$ e $600 \mu \mathrm{g} / \mathrm{kg}$ de cromo) e seis repetições de 50 aves por unidade experimental. A utilização do tripicolinato de cromo não teve efeito no desempenho dos frangos de corte. Os níveis de cromo não influenciaram o rendimento de carcaça nem o $\mathrm{pH}$ do peito dos frangos aos 42 dias de idade. Em avaliação da composição de matéria seca, proteína bruta e extrato etéreo da carne de peito, apenas a porcentagem de extrato etéreo foi influenciada, e de forma quadrática, pelos níveis de cromo na dieta. O nível de 218,2 $\mu \mathrm{g}$ de cromo diminuiu a porcentagem de extrato etéreo em 7,03 em comparação à ausência de cromo. A suplementação de cromo nas dietas não influenciou o teor de colesterol total na carne do peito, mas alterou os níveis de HDL aos 14 dias de idade e os de VLDL e os triglicérides aos 21 dias de idade. A suplementação dietética de cromo não influenciou o desempenho e rendimento de carcaça. Níveis entre 218,2 e 360,3 ìg de cromo interferem no teor de gordura da carne e nos níveis de lipídeos do sangue dos frangos de corte.

Palavras-chave: colesterol na carne, desempenho, lipídeos, rendimento de carcaça

\section{Chromium influence on performance, meat quality and concentration of lipids in broiler blood plasma}

\begin{abstract}
The aim of this work was to evaluate the effect of dietary chromium supplementation on performance, carcass yield, meat quality, cholesterol level on the breast and blood biochemical parameters on broilers. It was used a complete randomized experimental design with five levels of chromium tripicolinate $(0,150,300,450$ and $600 \mu \mathrm{g} / \mathrm{kg}$ of chromium) and six replicates with 50 broilers per experimental unit. The use of chromium tripicolinate had no effect on the performance of broilers. The levels of chromium did not change the carcass yield neither the breast $\mathrm{pH}$ of the broilers at 42 days of age. At evaluation of dry matter composition, crude protein and ether extract of breast meal, only the percentage of ether extract was quadractly affected by the dietary chromium level. Chromium level of $218.2 \mu \mathrm{g}$ reduced the ether extract percentage by 7.03 when compared to the lack of chromium. The addition of chromium in the diets did not influence the total cholesterol level in the breast meat but it did change the levels of HDL at 14 old, the VLDL and triglicerides at 21 days old. The dietery suplementation of chromium did not influence the performance neither the carcass yield. Levels of chromium ranging from 218.2 to $360.3 \mathrm{ì} \mathrm{g}$ affects fat meat and levels of blood lipids of broiler chickens.
\end{abstract}

Key Words: carcass yield, lipids, meat cholesterol, performance

\section{Introdução}

A produção e o consumo mundial de carne de frangos de corte têm elevado significamente nos últimos anos.

Os frangos de corte têm se tornado cada vez mais precoces e com elevado ganho de peso, por outro lado, tem-se observado aumento do acúmulo de gordura na carcaça, principalmente na região abdominal. A composição da carcaça e o rendimento de carne dependem de vários fatores, como nutrição, manejo e condições de ambiente.
A qualidade da carne de frangos está relacionada ao teor de gordura na carcaça e a síntese de gordura é bem mais dispendiosa que a do tecido muscular. Os meios utilizados para reduzir a gordura na carcaça de frangos são o melhoramento genético, a adequação dos níveis de energia e proteína da dieta e a utilização de alguns suplementos e aditivos. Entre os suplementos, tem merecido destaque o cromo trivalente $\left(\mathrm{Cr}^{+3}\right)$, reconhecido como elemento- traço essencial no metabolismo de carboidratos, proteínas e lipídeos como componente ativo do fator de tolerância à

Recebido em 5/12/2007 e aprovado em 1/4/2009.

Correspondências devem ser enviadas para:Imgsouza@hotmail.com 
glicose (GTF) (Mertz, 1992), uma vez que, por agir estimulando a sensibilidade à insulina (Vicent, 2000), pode influenciar também no metabolismo proteico, estimulando a captação de aminoácidos e aumentando a síntese protéica (Clarkson, 1997).

Em aves, a suplementação de cromo orgânico $\left(\mathrm{Cr}^{+3}\right)$ melhora a velocidade de crescimento, a eficiência alimentar, o rendimento de carne e a qualidade de carcaça por reduzir a quantidade de gordura (Gursoy, 2000).

Este trabalho foi realizado para avaliar o efeito da suplementação dietética de cromo sobre o desempenho, o rendimento de carcaça, a qualidade da carne, o teor de colesterol no peito e os parâmetros bioquímicos do sangue de frangos de corte.

\section{Material e Métodos}

O experimento foi conduzido no setor de avicultura da Fazenda Experimental de Iguatemi, da Universidade Estadual de Maringá, sob aprovação do Comitê de Ética em Experimentação Animal - CEEA/UEM (Registro Nº47/ 2006).

Foram utilizados 1.500 pintos de corte machos de 1 dia de idade com peso médio de 45,07 g, marca comercial Cobb - Vantress ${ }^{\circledR}$. As aves foram alojadas em um galpão convencional (30 $\mathrm{m}$ de comprimento e $8 \mathrm{~m}$ de largura), com cobertura de telha francesa e lanternim, piso de concreto e paredes laterais de alvenaria com $40 \mathrm{~cm}$ de altura, e o restante da parede completado com tela de arame até o telhado e provido de cortinas móveis. O galpão foi dividido em 30 boxes de $6,3 \mathrm{~m}^{2}$, cada um com capacidade para 50 aves, e forrado com palha de arroz como cama.

$\mathrm{Na}$ fase inicial, foram utilizados comedouros infantis e bebedouros do tipo copo de pressão até o quinto dia de idade, quando foram substituídos gradativamente por comedouros tubulares e bebedouros automáticos do tipo pendular. Em cada boxe, foram utilizados um círculo de proteção e uma campânula como fonte de aquecimento para os pintinhos. Água e ração foram fornecidas à vontade em um programa de alimentação dividido em duas fases, a inicial do $1^{\circ}$ aos 21 dias de idade e a de crescimento, dos 22 aos 42 dias de idade.

O delineamento experimental utilizado foi o inteiramente casualizado, com cinco níveis de tripicolinato de cromo a $0,4 \%$ como fonte do mineral orgânico $(0,150,300,450$ e $600 \mu \mathrm{g} / \mathrm{kg}$ de cromo) e seis repetições de 50 aves por unidade experimental. Os níveis de tripicolinato de cromo foram utilizados durante todo o período experimental (1 a 42 dias de idade). As rações experimentais foram formuladas à base de milho e farelo de soja, de modo a atender às exigências nutricionais de cada fase de acordo com recomendações de Rostagno et al. (2005) (Tabelas 1 e 2).

As aves e as rações foram devidamente pesadas aos 1 , 7, 14, 21 e 42 dias de idade, para avaliação do desempenho (consumo de ração, ganho de peso e conversão alimentar). A mortalidade e as sobras de ração foram devidamente registradas para determinação do real consumo de ração pelas aves.

A cama utilizada foi de palha de arroz (primeiro uso). As aves foram vacinadas no incubatório contra a doença de Marek e, após o alojamento, não receberam nenhuma vacina. Utilizou-se um programa de luz contínua durante os primeiros dez dias e o restante do período experimental com 23 horas de luz/dia. As temperaturas médias dentro do galpão foram de: máxima de $30^{\circ} \mathrm{C}$ e mínima de $23^{\circ} \mathrm{C}$ e a umidade relativa média, de $74 \%$. O percentual de mortalidade registrado durante todo o período experimental foi de $3,06 \%$.

Para o rendimento de carcaça e seus respectivos cortes, aos 42 dias de idade, duas aves por unidade experimental, escolhidas ao acaso, foram submetidas a jejum alimentar por 6 horas e abatidas por atordoamento por choque elétrico (220W) e posterior sangria.

No cálculo do rendimento de carcaça, foi considerado o peso da carcaça eviscerada, sem pés, cabeça e gordura abdominal, em relação ao peso vivo das aves, que foi determinado individualmente antes do abate. Antes do abate, as aves foram identificadas por meio de anilhas numeradas colocadas na asa. No rendimento dos cortes nobres, foi considerado o peito inteiro com pele e ossos e pernas (coxa e sobrecoxa com ossos e pele), que foi calculado em relação ao peso da carcaça eviscerada. As amostras de peito permaneceram em câmara fria a $3^{\circ} \mathrm{C}$ durante 24 horas, para posterior análise.

A gordura abdominal em torno da cloaca, da bolsa cloacal, da moela, do proventrículo e dos músculos abdominais adjacentes foi retirada conforme descrito por Smith (1993), e pesada e também calculada em relação ao peso da carcaça eviscerada.

A determinação do $\mathrm{pH}$ foi realizada diretamente no filé do peito de duas aves por unidade experimental, com auxílio de um peagâmetro TECNAL ${ }^{\circledR} 24$ horas post mortem. O ponto de incisão do eletrodo foi a parte cranial ventral do filé, conforme descrito por Boulianne \& King (1995).

Aos 7, 14, 21 e 42 dias de idade, foram coletadas amostras de sangue de duas aves por unidade experimental, na veia braquial, para realização do lipidograma total no soro dessas aves, utilizando-se o kit comercial Labtest ${ }^{\circledR}$.

Para a extração e quantificação de colesterol na carne, os peitos retirados na análise do rendimento de carcaça, dois por unidade experimental, foram moídos e uma amostra 
Tabela 1 - Composição das rações experimentais fornecidas na fase de 1 a 21 dias de idade

\begin{tabular}{|c|c|c|c|c|c|}
\hline \multirow[b]{2}{*}{ Ingrediente } & \multicolumn{5}{|c|}{ Nível de cromo ( $\mu \mathrm{g} / \mathrm{kg}$ de ração) } \\
\hline & 0 & 150 & 300 & 450 & 600 \\
\hline Milho grão & 53,66 & 53,52 & 53,48 & 53,44 & 53,41 \\
\hline Farelo de soja $45 \%$ & 37,12 & 37,12 & 37,12 & 37,12 & 37,12 \\
\hline Fosfato bicálcico & 1,86 & 1,86 & 1,86 & 1,86 & 1,86 \\
\hline Calcário & 0,91 & 0,91 & 0,91 & 0,91 & 0,91 \\
\hline Bicarbonato de sódio & 0,22 & 0,22 & 0,22 & 0,22 & 0,22 \\
\hline Óleo de soja & 5,16 & 5,26 & 5,26 & 5,26 & 5,26 \\
\hline Sal comum & 0,29 & 0,29 & 0,29 & 0,29 & 0,29 \\
\hline DL-metionina $98 \%$ & 0,299 & 0,299 & 0,299 & 0,299 & 0,299 \\
\hline L-lisina $\mathrm{HCl} 78 \%$ & 0,236 & 0,236 & 0,236 & 0,236 & 0,236 \\
\hline L-treonina $98 \%$ & 0,077 & 0,077 & 0,077 & 0,077 & 0,077 \\
\hline Cloreto de colina $70 \%$ & 0,016 & 0,016 & 0,016 & 0,016 & 0,016 \\
\hline Suplemento mineral e vitamínico ${ }^{1,2}$ & 0,150 & 0,150 & 0,150 & 0,150 & 0,150 \\
\hline Cromo $^{3}$ & 0,00 & 0,038 & 0,075 & 0,113 & 0,150 \\
\hline Butil-hidroxi-tolueno & 0,010 & 0,010 & 0,010 & 0,010 & 0,010 \\
\hline \multicolumn{6}{|l|}{ Valores nutricionais } \\
\hline Energia metabolizável (kcal/kg) & 3.100 & 3.100 & 3.100 & 3.100 & 3.100 \\
\hline Proteína bruta (\%) & 21,4 & 21,4 & 21,4 & 21,4 & 21,4 \\
\hline Cálcio (\%) & 0,911 & 0,911 & 0,911 & 0,911 & 0,911 \\
\hline Fósforo disponível (\%) & 0,455 & 0,455 & 0,455 & 0,455 & 0,455 \\
\hline Metionina + cistina $(\%)$ & 0,962 & 0,962 & 0,962 & 0,962 & 0,962 \\
\hline Lisina $(\%)$ & 1,345 & 1,345 & 1,345 & 1,345 & 1,345 \\
\hline Treonina $(\%)$ & 0,913 & 0,913 & 0,913 & 0,913 & 0,913 \\
\hline Arginina $(\%)$ & 1,45 & 1,45 & 1,45 & 1,45 & 1,45 \\
\hline
\end{tabular}

${ }^{1}$ Suplemento vitamínico inicial (conteúdo por kg de premix): vit. A - 7.000.000,00 UI; vit. D3 - 2.200.000,00 UI; vit.E - $11.000,00 \mathrm{mg}$; vit. K3 - 1.600,00 mg; vit. B1 $2.000,00 \mathrm{mg}$; vit. B2 - 5.000,00 mg, vit. B12 - 12.000,00 mcg; niacina - 35.000,00 mg; ácido pantotênico - 13.000,00 mg; ácido fólico - 800,00 mg; antioxidante $100.000,00$; veículo q.s.p. - $1.000,00 \mathrm{~g}$.

2 Suplemento mineral (conteúdo por kg de premix): Fe - 10.000,00 mg; Cu - 16.000,00 mg; I - 2.400,00 mg; Zn - 100.000,00 mg; Mn - 140.000,00 mg; Se - 400,00 mg; veículo

3 q.s.p. - $1.000,00$ g.

Tabela 2 - Composição das rações experimentais fornecidas na fase de 22 a 42 dias de idade

\begin{tabular}{|c|c|c|c|c|c|}
\hline \multirow[b]{2}{*}{ Ingrediente } & \multicolumn{5}{|c|}{ Nível de cromo ( $\mu \mathrm{g} / \mathrm{kg}$ de ração) } \\
\hline & 0 & 150 & 300 & 450 & 600 \\
\hline Milho grão & 59,250 & 59,05 & 59,02 & 58,98 & 58,94 \\
\hline Farelo de soja $45 \%$ & 31,63 & 31,68 & 31,68 & 31,68 & 31,68 \\
\hline Fosfato bicálcico & 1,66 & 1,66 & 1,66 & 1,66 & 1,66 \\
\hline Calcário & 0,853 & 0,853 & 0,853 & 0,853 & 0,853 \\
\hline Óleo de soja & 5,56 & 5,66 & 5,66 & 5,66 & 5,66 \\
\hline Sal comum & 0,417 & 0,417 & 0,417 & 0,417 & 0,417 \\
\hline DL-metionina $98 \%$ & 0,234 & 0,234 & 0,234 & 0,234 & 0,234 \\
\hline L-lisina $\mathrm{HCl} 78 \%$ & 0,188 & 0,188 & 0,188 & 0,188 & 0,188 \\
\hline L-treonina $98 \%$ & 0,039 & 0,039 & 0,039 & 0,039 & 0,039 \\
\hline Cloreto de colina $70 \%$ & 0,017 & 0,017 & 0,017 & 0,017 & 0,017 \\
\hline Suplemento mineral e vitamínico ${ }^{1,2}$ & 0,150 & 0,150 & 0,150 & 0,150 & 0,150 \\
\hline $\mathrm{Cromo}^{3}$ & 0,000 & 0,038 & 0,075 & 0,113 & 0,150 \\
\hline Butil-hidroxi-tolueno & 0,010 & 0,010 & 0,010 & 0,010 & 0,010 \\
\hline \multicolumn{6}{|l|}{ Valores nutricionais } \\
\hline Energia metabolizável (kcal/kg) & 3.200 & 3.200 & 3.200 & 3.200 & 3.200 \\
\hline Proteína bruta $(\%)$ & 19,410 & 19,410 & 19,410 & 19,410 & 19,410 \\
\hline Cálcio (\%) & 0,824 & 0,824 & 0,824 & 0,824 & 0,824 \\
\hline Fósforo disponível (\%) & 0,411 & 0,411 & 0,411 & 0,411 & 0,411 \\
\hline Metionina + cistina $(\%)$ & 0,850 & 0,850 & 0,850 & 0,850 & 0,850 \\
\hline Lisina (\%) & 1,170 & 1,170 & 1,170 & 1,170 & 1,170 \\
\hline Treonina (\%) & 0,797 & 0,797 & 0,797 & 0,797 & 0,797 \\
\hline Arginina (\%) & 1,290 & 1,290 & 1,290 & 1,290 & 1,290 \\
\hline
\end{tabular}

${ }^{1}$ Mistura vitamínica de crescimento (conteúdo por kg de premix): vit. A - 6.000.000,00 UI; vit. D3 - 2.000.000,00 UI; vit. E - 10.000,00 mg; vit. K3 - 1.000,00 mg; vit. B1 - 1.400,00 mg; vit B2 - 4.000,00 mg; vit. B12 - 10.000,00 mcg; niacina - 30.000,00 mg; ácido pantotênico - $11.000,00 \mathrm{mg}$; ácido fólico - $600,00 \mathrm{mg}$; antioxidante $100.000,00$; veículo q.s.p. - $1.000,00 \mathrm{~g}$.

${ }^{2}$ Mistura mineral (conteúdo por kg de premix): Fe - 10.000,00 mg; Cu - 16.000,00 mg; I - 2.400,00 mg; Zn - 100.000,00 mg; Mn - 140.000,00 mg; Se - 400,00 mg; veículo q.s.p. $-1.000,00$ g.

3 Cromo (mineral orgânico - tripicolinato de cromo $0,04 \%$, MCASSAB). 
foi submetida ao método da saponificação direta, descrito por Al Hasani et al. (1993). Foram determinados ainda os teores de matéria seca, proteína bruta e extrato etéreo das amostras de peitos, conforme metodologia descrita por Silva \& Queiroz (2004).

Os dados obtidos foram desdobrados em polinômios ortogonais de forma a permitir a análise de variância e regressão de acordo com suas distribuições, utilizando-se o programa estatístico SAEG ${ }^{\circledR}(\mathrm{UFV}, 1997)$.

O modelo estatístico adotado foi: $\mathrm{Y}_{\mathrm{i}}=\mu+\mathrm{T}_{\mathrm{i}}+\mathrm{e}_{\mathrm{ij}}$, em que: $\mathrm{Y}_{\mathrm{i}}=$ valor observado das variáveis estudadas; $\mu=$ média geral de todas as observações; $\mathrm{T}_{\mathrm{i}}=$ efeito do nível $\mathrm{i}$ de cromo, $\mathrm{i}=(0,150,300,450$ e $600 \mu \mathrm{g} \mathrm{Cr} / \mathrm{kg})$; e $\mathrm{e}_{\mathrm{ij}}=$ erro experimental.

\section{Resultados e Discussão}

A utilização do tripicolinato de cromo não teve efeito $(\mathrm{P}>0,05)$ no desempenho dos frangos de corte em nenhuma das fases de criação (Tabela 3). Resultados semelhantes foram verificados por Oba et al. (2007), em frangos de corte alimentados com 0, 400, 800 e $1.200 \mu \mathrm{g} \mathrm{Cr} / \mathrm{kg}$ na forma de cromo complexado à levedura, e Chen et al. (2001), que suplementaram dietas para perus com cromo nicotinato nos níveis de 0,1 e $3 \mathrm{mg} / \mathrm{kg}$, e não verificaram efeitos do cromo sobre o peso das aves, o consumo de ração e a conversão alimentar.
Lee et al. (2003) também verificaram que a adição de cromo picolinato à dieta de frangos de corte de 0,200 e 400 ppb não afetou o desempenho dessas aves, confirmando observações de Motozono et al. (1998).

Diferentemente do presente trabalho, Neto et al. (2009) trabalhando com bovinos a pasto, verificaram que a suplementação mineral protéica com adição de cromo complexado à molécula orgânica aumentou o ganho de peso e o rendimento de carcaça, porém não verificaram influencia sobre os parâmetros qualitativos da carne. Araújo et al. (2007) avaliando níveis de cromo para codornas japonesas de postura verificaram que o nível de 500ppb de Cr na dieta aumenta a produção de ovos comercializáveis.

Não houve efeito $(\mathrm{P}>0,05)$ dos níveis de cromo sobre o rendimento de carcaça e cortes (Tabela 4). Da mesma forma, Anandhi et al. (2006) não notaram influência da inclusão de cromo na dieta sobre o rendimento de carcaça, o peso e as porcentagens de coração, fígado e moela, o rendimento de cortes e a porcentagem de gordura abdominal de frangos de corte.

Depois de 24 horas post mortem, as amostras dos peitos das aves foram avaliadas para determinação do $\mathrm{pH}$, o qual não sofreu qualquer alteração atribuível ao nível de cromo da dieta. Os valores de $\mathrm{pH}$ estão dentro da faixa considerada normal, ou seja, superior a 5,7 e inferior a 6,2. Segundo Kijowski \& Niewiarowicz (1978), o pH de 5,7 obtido após 15 minutos reflete Pale Soft Exudative (PSE)

Tabela 3 - Desempenho de frangos de corte de 1 a 42 dias de idade alimentados com dietas suplementadas com cromo

\begin{tabular}{|c|c|c|c|c|}
\hline Período (dias) & Peso final (g) & Ganho de peso $(\mathrm{g})$ & Consumo de ração (g/ave) & Conversão alimentar (g/g) \\
\hline 1 a 7 & $196,69 \pm 0,94$ & $151,63 \pm 0,95$ & $154,32 \pm 0,58$ & $1,018 \pm 0,005$ \\
\hline CV (\%) & 2,394 & 3,084 & 1,929 & 2,777 \\
\hline 1 a 14 & $552,56 \pm 1,89$ & $507,49 \pm 1,88$ & $369,17 \pm 2,91$ & $0,727 \pm 0,004$ \\
\hline CV (\%) & 1,831 & 1,954 & 4,501 & 3,685 \\
\hline 1 a 21 & $1035,70 \pm 4,09$ & $990,63 \pm 4,09$ & $1039,41 \pm 8,64$ & $1,049 \pm 0,008$ \\
\hline CV (\%) & 2,162 & 2,264 & 4,845 & 4,680 \\
\hline 1 a 41 & $2760,71 \pm 12,22$ & $2715,65 \pm 12,35$ & $4171,56 \pm 15,16$ & $1,536 \pm 0,008$ \\
\hline CV (\%) & 2,485 & 2,534 & 2,111 & 3,093 \\
\hline
\end{tabular}

Não-significativo $(\mathrm{P}>0,05)$. CV $=$ coeficiente de variação.

Tabela 4 - Rendimento de carcaça de frangos de corte alimentados com dietas suplementadas com cromo

\begin{tabular}{|c|c|c|c|c|c|c|}
\hline & \multicolumn{5}{|c|}{ Nível de cromo ( $\mu \mathrm{g} / \mathrm{kg}$ de ração) } & \multirow[t]{2}{*}{$\mathrm{CV} \%$} \\
\hline & 0 & 150 & 300 & 450 & 600 & \\
\hline Peso (g) & $2892,08 \pm 27,63$ & $2916,67 \pm 29,73$ & $2892,08 \pm 50,96$ & $2944,58 \pm 55,52$ & $2851,67 \pm 31,91$ & 3,45 \\
\hline Peso eviscerado (g) & $1969,83 \pm 29,92$ & $2023,83 \pm 44,23$ & $1983,83 \pm 40,87$ & $2030,83 \pm 49,79$ & $1987,33 \pm 28,04$ & 4,84 \\
\hline$\%$ Peito & $35,67 \pm 0,20$ & $36,30 \pm 0,73$ & $36,63 \pm 0,43$ & $35,63 \pm 0,41$ & $36,23 \pm 0,45$ & 3,24 \\
\hline$\%$ Coxa & $31,83 \pm 0,19$ & $30,55 \pm 0,32$ & $31,39 \pm 0,64$ & $31,38 \pm 0,43$ & $30,68 \pm 0,35$ & 3,27 \\
\hline$\%$ Gordura & $2,41 \pm 0,21$ & $2,34 \pm 0,25$ & $2,73 \pm 0,12$ & $2,46 \pm 0,13$ & $2,25 \pm 0,15$ & 18,33 \\
\hline Rendimento $(\%)$ & $68,08 \pm 0,6$ & $69,37 \pm 1,10$ & $68,59 \pm 0,32$ & $69,00 \pm 0,86$ & $69,71 \pm 0,46$ & 2,60 \\
\hline
\end{tabular}




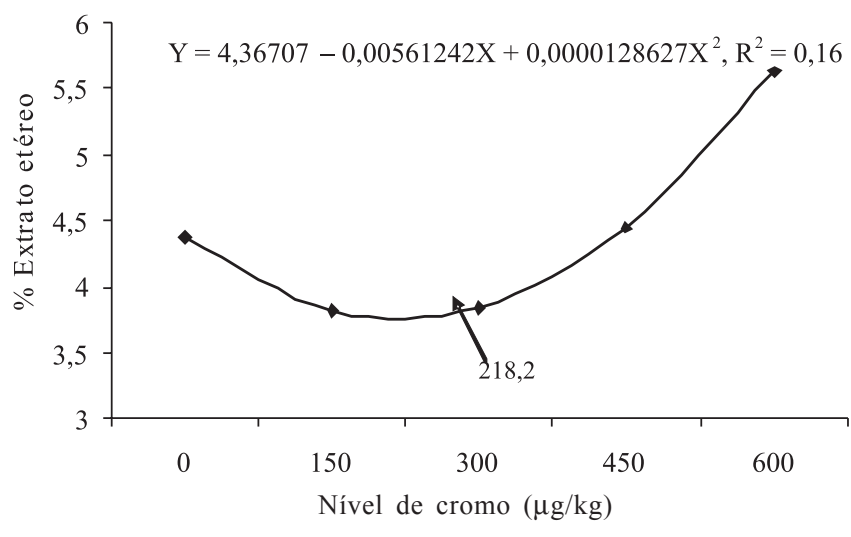

Figura 1 - Porcentagem de extrato etéreo na carne do peito de frangos de corte aos 42 dias de idade alimentados com dietas suplementadas com cromo.

em carnes de frangos, no entanto, o pH médio do músculo do peito neste estudo foi de 6,0 .

Apenas a porcentagem de extrato etéreo foi influenciada e de forma quadrática $(\mathrm{P}<0,05)$, pelos níveis de cromo na dieta. O nível de $218,2 \mu \mathrm{g} / \mathrm{kg}$ de cromo diminuiu em 7,03\% a porcentagem de extrato etéreo em comparação ao grupo controle (Tabela 5), logo a suplementação com esse nível de cromo foi eficiente na redução da gordura da carne do peito dos frangos (Figura 1, Tabela 5). Segundo Vicent (2000), o cromo é um elemento-traço essencial no metabolismo de carboidratos e lipídios, por agir estimulando a sensibilidade das células à insulina. A insulina promove o transporte dos carboidratos para o interior das células, aciona a atividade das enzimas celulares que facilitam a síntese proteica e acelera o catabolismo dos ácidos graxos.

A carne de frangos de corte, principalmente a do peito apresenta, baixo teor de gordura em comparação às carnes vermelhas, entretanto deve ser constante a busca por alternativas para a redução desse componente, como a inclusão de cromo nas dietas das aves.

Os níveis de cromo na dieta afetaram $(\mathrm{P}<0,05)$ as concentrações de HDL aos 14 dias de idade, e de VLDL e triglicérides aos 21 dias de idade (Figura 2). Aos 14 dias de

Tabela 5 - Composição nutricional da carne de peito de frangos de corte alimentados com dietas suplementadas com cromo

\begin{tabular}{ccccc}
\hline Níveis de cromo $(\mu \mathrm{g} / \mathrm{kg})$ & $\% \mathrm{MS}$ & $\% \mathrm{~PB}$ & $\% \mathrm{EE}$ & Colesterol total $(\mathrm{mg} / 100 \mathrm{~g})$ \\
\hline 0 & $24,83 \pm 0,229$ & $84,48 \pm 1,110$ & $4,27 \pm 0,412$ & $46,70 \pm 2,16$ \\
150 & $27,02 \pm 1,725$ & $84,87 \pm 1,194$ & $3,97 \pm 0,620$ & $43,65 \pm 2,50$ \\
300 & $24,95 \pm 0,284$ & $84,83 \pm 1,524$ & $3,93 \pm 0,436$ & $51,66 \pm 1,96$ \\
450 & $24,90 \pm 0,198$ & $84,30 \pm 1,865$ & $4,17 \pm 0,442$ & $47,39 \pm 3,65$ \\
600 & $25,23 \pm 0,191$ & $82,21 \pm 1,322$ & $5,75 \pm 1,138$ & $45,10 \pm 4,17$ \\
CV\% & 7,71 & 4,16 & 37,08 & 15,54 \\
\hline
\end{tabular}

Não-significativo $(\mathrm{P} \geq 0,05)$.

Tabela 6 - Níveis de colesterol e triglicérides no soro de frangos de corte alimentados com dietas suplementadas com cromo

\begin{tabular}{|c|c|c|c|c|c|c|}
\hline $\begin{array}{l}\text { Nível de } \\
\text { cromo }(\mu \mathrm{g} / \mathrm{kg})\end{array}$ & $\begin{array}{l}\text { Idade } \\
\text { (dias) }\end{array}$ & $\begin{array}{l}\text { Colesterol } \\
\text { total }(\mathrm{mg} / \mathrm{dL})\end{array}$ & $\begin{array}{c}\mathrm{HDL} \\
(\mathrm{mg} / \mathrm{dL})\end{array}$ & $\begin{array}{c}\mathrm{LDL} \\
(\mathrm{mg} / \mathrm{dL})\end{array}$ & $\begin{array}{c}\text { VLDL } \\
(\mathrm{mg} / \mathrm{dL})\end{array}$ & $\begin{array}{l}\text { Triglicérides } \\
(\mathrm{mg} / \mathrm{dL})\end{array}$ \\
\hline \multirow[t]{4}{*}{ Controle } & 7 & $129,33 \pm 6,13$ & $93,50 \pm 7,97$ & $11,67 \pm 2,43$ & $24,17 \pm 4,00$ & $120,53 \pm 20,04$ \\
\hline & 14 & $127,83 \pm 3,17$ & $100,33 \pm 2,75$ & $13,23 \pm 3,29$ & $14,27 \pm 2,33$ & $71,33 \pm 11,66$ \\
\hline & 21 & $92,33 \pm 3,41$ & $70,33 \pm 2,61$ & $6,73 \pm 2,61$ & $15,27 \pm 1,96$ & $76,33 \pm 9,80$ \\
\hline & 41 & $92,67 \pm 6,16$ & $74,00 \pm 4,09$ & $13,06 \pm 2,84$ & $5,60 \pm 0,63$ & $28,00 \pm 3,17$ \\
\hline \multirow[t]{4}{*}{150} & 7 & $137,66 \pm 4,21$ & $102,17 \pm 6,45$ & $14,07 \pm 4,57$ & $21,43 \pm 2,65$ & $107,17 \pm 13,28$ \\
\hline & 14 & $112,50 \pm 8,06$ & $88,50 \pm 4,85$ & $10,13 \pm 3,20$ & $13,87 \pm 2,04$ & $69,33 \pm 10,22$ \\
\hline & 21 & $88,50 \pm 6,38$ & $67,67 \pm 4,92$ & $12,57 \pm 2,39$ & $8,27 \pm 0,87$ & $41,33 \pm 4,35$ \\
\hline & 41 & $94,67 \pm 4,05$ & $76,00 \pm 2,70$ & $12,97 \pm 1,82$ & $5,70 \pm 0,68$ & $28,50 \pm 3,43$ \\
\hline \multirow[t]{4}{*}{300} & 7 & $123,50 \pm 7,50$ & $89,67 \pm 3,73$ & $11,53 \pm 1,95$ & $22,30 \pm 3,74$ & $111,50 \pm 18,72$ \\
\hline & 14 & $119,33 \pm 5,78$ & $91,00 \pm 4,02$ & $13,10 \pm 2,12$ & $15,23 \pm 1,75$ & $76,17 \pm 8,76$ \\
\hline & 21 & $85,83 \pm 4,31$ & $68,17 \pm 3,78$ & $7,97 \pm 3,21$ & $9,70 \pm 1,46$ & $48,50 \pm 7,30$ \\
\hline & 41 & $104,67 \pm 4,51$ & $84,67 \pm 3,17$ & $14,23 \pm 2,30$ & $5,77 \pm 0,77$ & $28,83 \pm 3,87$ \\
\hline \multirow[t]{4}{*}{450} & 7 & $144,50 \pm 12,63$ & $107,50 \pm 7,91$ & $10,93 \pm 3,53$ & $26,06 \pm 5,87$ & $130,33 \pm 29,38$ \\
\hline & 14 & $118,33 \pm 7,46$ & $95,67 \pm 3,30$ & $9,10 \pm 4,53$ & $13,57 \pm 1,50$ & $67,83 \pm 7,53$ \\
\hline & 21 & $91,83 \pm 11,44$ & $68,17 \pm 7,00$ & $13,30 \pm 4,83$ & $10,37 \pm 2,32$ & $51,83 \pm 11,64$ \\
\hline & 41 & $84,67 \pm 7,60$ & $72,33 \pm 5,80$ & $8,67 \pm 1,66$ & $3,67 \pm 0,22$ & $18,33 \pm 1,11$ \\
\hline \multirow[t]{4}{*}{600} & 7 & $135,33 \pm 8,05$ & $102,50 \pm 6,87$ & $6,10 \pm 0,92$ & $26,73 \pm 3,40$ & $133,67 \pm 17,00$ \\
\hline & 14 & $119,50 \pm 5,88$ & $97,83 \pm 3,78$ & $9,96 \pm 2,48$ & $11,70 \pm 1,73$ & $58,50 \pm 8,65$ \\
\hline & 21 & $82,66 \pm 3,74$ & $62,00 \pm 4,10$ & $10,27 \pm 1,86$ & $10,40 \pm 1,54$ & $52,00 \pm 7,73$ \\
\hline & 41 & $88,50 \pm 6,20$ & $72,50 \pm 3,52$ & $10,00 \pm 1,80$ & $6,00 \pm 1,29$ & $30,00 \pm 6,46$ \\
\hline
\end{tabular}




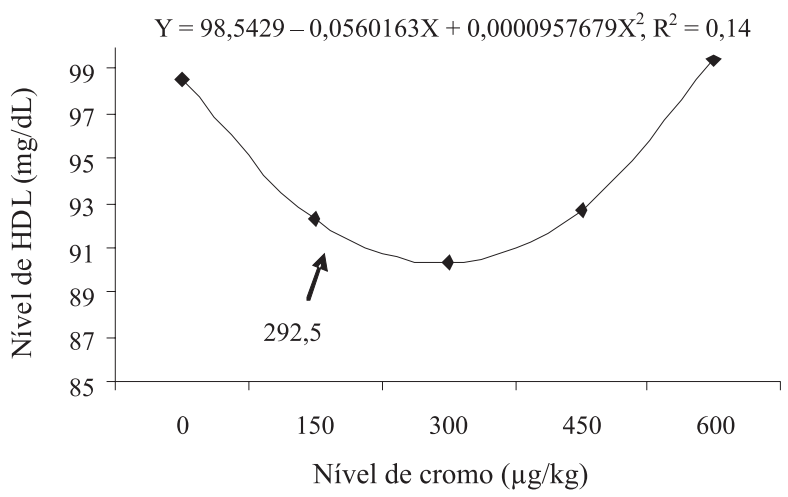

$$
\mathrm{Y}=14,2267-0,0304224 \mathrm{X}+0,0000422226 \mathrm{X}^{2}, \mathrm{R}^{2}=0,18
$$
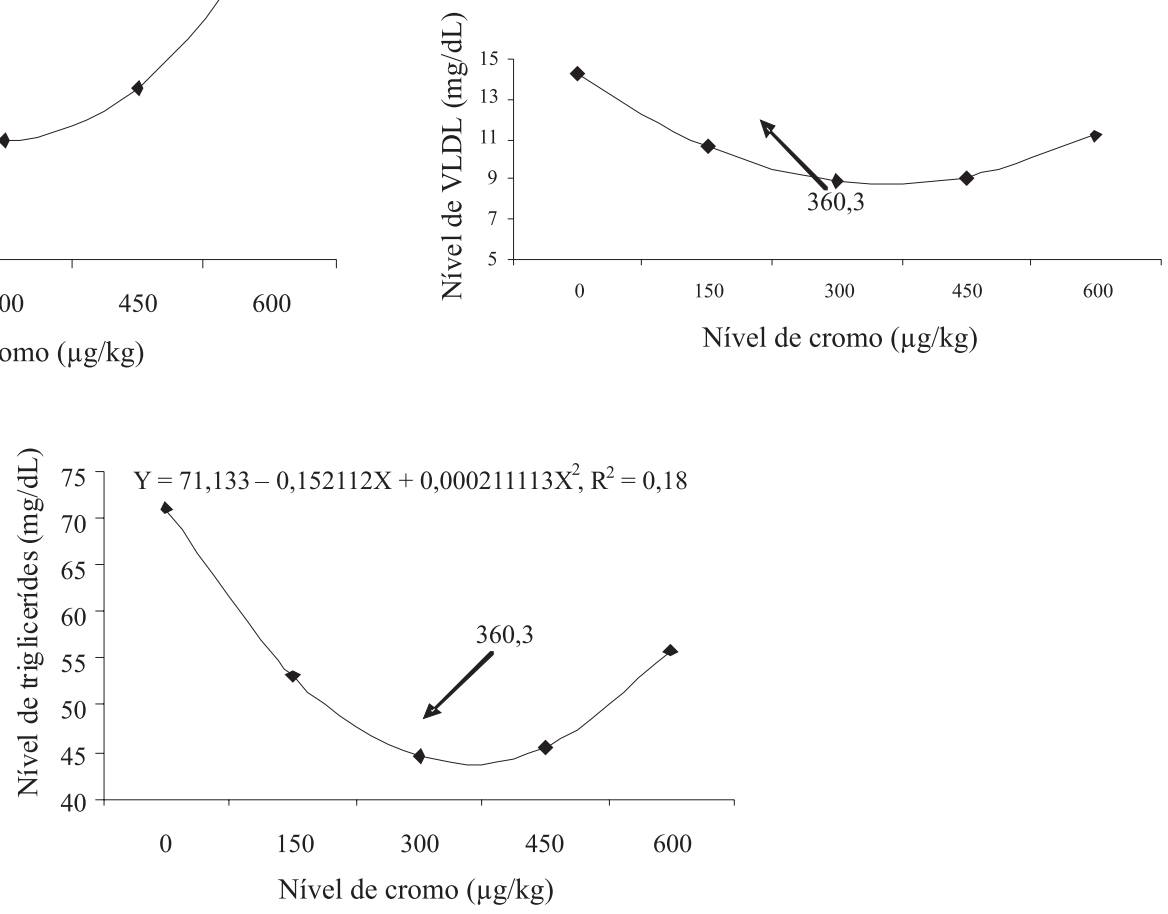

Figura 2 - Níveis sorológicos de HDL, VLDL e triglicérides de frangos de corte alimentados com dietas suplementadas com cromo.

idade, verificou-se aumento $(\mathrm{P}<0,05)$ dos níveis de HDL no soro de frangos de corte alimentados com rações contendo cromo em níveis a partir de 292,5 $\mu \mathrm{g} / \mathrm{kg}$ (Tabela 6). Aos 21 dias de idade, os menores valores de $\operatorname{VLDL}(8,74 \mathrm{mg} / \mathrm{dL}$ de soro) foram obtidos com o nível de $360,3 \mu \mathrm{g}$ de cromo $(\mathrm{P}<0,05)$ e o menor valor de triglicérides com $289,2 \mu \mathrm{g}$ de cromo (44,79 mg/dL de soro).

Segundo Press et al. (1990), o cromo reduz as concentrações de lipídios, colesterol total e lipoproteína de baixa densidade (LDL) e aumenta as lipoproteínas de alta densidade (HDL) no sangue. Isso provavelmente ocorre porque o cromo parece agir inibindo a enzima hidroximetilglutaril-CoA redutase, responsável pela síntese de colesterol, diminuindo a concentração plasmática de colesterol no organismo.

Resultados semelhantes foram encontrados por Króliczewska et al. (2004), que suplementaram a dieta de frangos de corte com cromo nos níveis de 0,300 e $500 \mu \mathrm{g} / \mathrm{kg}$ e observaram redução nas concentrações de colesterol total, LDL, triglicérides e glicose e aumento nos níveis de HDL. Lien et al. (2001) também avaliaram a suplementação de cromo na dieta frangos de corte $(1.600$ e $3.200 \mu \mathrm{g} / \mathrm{kg}) \mathrm{e}$ verificaram diminuição dos níveis de glicose, VLDL e LDL e aumento de triglicérides e HDL. Uyanik et al. (2002) suplementaram a dieta de poedeiras com 20 ppm de cromo e não notaram redução significativa dos níveis sorológicos de colesterol total, apesar da queda nos níveis de triglicérides. Por outro lado, Sands \& Smith (2002) utilizaram picolinato de cromo e manganês proteinado na dieta de frangos de corte e não observaram variação nas concentrações sorológicas de ácidos graxos nãoesterificados, triglicérides, HDL e colesterol total, porém os níveis de ácidos graxos não- esterificados tenderam a uma diminuição. Kim et al. (1995) relataram aumento dos níveis de HDL, redução do colesterol total e elevada relação HDL:CHOL em frangos sob suplementação com picolinato de cromo.

O cromo pode interferir no metabolismo das gorduras, diminuindo os níveis de colesterol LDL e aumentando os de HDL. Neste estudo, apesar da diminuição dos níveis de VLDL e triglicérides aos 21 dias e do aumento do HDL aos 14 dias, esses parâmetros sorológicos não se mantiveram até a idade de abate, o que seria desejável.

\section{Conclusões}

A suplementação dietética de cromo não influencia o desempenho nem o rendimento de carcaça, porém o nível de $218,2 \mu \mathrm{g}$ de cromo diminui a quantidade de gordura na carne de peito. Com o fornecimento de 292,5 $\mu \mathrm{g}$ de cromo, os 
níveis de HDL aumentaram aos 14 dias de idade. Menores níveis de triglicérides e VLDL no sangue podem ser obtidos com o nível de 360,3 $\mu \mathrm{g}$ de cromo, porém essa redução ocorre apenas aos 21 dias de idade.

\section{Referências}

AL-HASANI, S. M.; HLAVAC, J.; CARPENTER, M.W. Rapid determination of cholesterol in single and multicomponent prepared foods. Journal of the Association Official Analytical Chemists International, v.76, p.902-906, 1993. ANANDHI, M.; MATHIVANAN, R.; VISWANATHAN, K. et al. Dietary inclusion of organic chromium on production and carcass characteristics of broilers. International Journal of Poultry Science, v.9, p.880-884, 2006.

ARAÚJO, M.S.; BARRETO, S.L.T.; DONZELE, J.L. et al. Níveis de cromo orgânico na dieta de codornas japonesas mantidas em estresse por calor na fase de postura. Revista Brasileira de Zootecnia, v.36, n.4, p.584-588, 2007.

BOULIANNE, M.; KING,A. J. Biochemical and color characteristics of skinless boneless pale chicken breast. Poultry Science, v.74, p.1693-1698, 1995.

CHEN, K.L.; LU, J.J.; LIEN, F.F. et al. Effects of chromium nicotinate on performance, carcase characteristics and blood chemistry of growing turkeys. British Poultry Science, v.42, p.399-404, 2001.

CLARKSON, P.M. Effects of exercise on chromium levels: is supplementation required? Sports Medicine, v.23, p.341-349, 1997.

GURSOY, U. Chromium in broiler diets. Feed International, v.21, n.3, p.24-26, 2000

KIM, S.W.; HAN, I.K.; SHIN, I.S. et al. Effects of supplemental chromium picolinato on growth performance, carcass composition and serum traits of broiler fed diets varying in protein and lysine. Asian Australian Journal of Animal Science, v.8, p.455-462, 1995.

KIJOWSKI, J.; NIEWIAROWICZ, A. Emulsifying properties of proteins and meat from broiler breast muscles as affected by their initial $\mathrm{pH}$ values. Journal Food Technology, v.13, p.451-459, 1978.

KRÓLICZEWSKA, B.; ZAWADZKI, W.; DOBRZANSKI, Z. et al. Changes in selected serum parameters of broiler chicken fed supplemental chromium. Journal Animal Physiology and Animal Nutrition, v.88, p.393-400, 2004.

LEE, D.N.;WU, F.Y.; CHENG, Y.H. et al. Effects of dietary chromium picolinate supplementation on growth performance and immune responses of broilers. Asian Australian Journal of Animal Science, v.16, p.227-233, 2003.

LIEN, T.F.; HORNG, Y.M.; YANG, K.H. Performance, serum characteristics, carcase traits and lipid metabolism of broilers as affected by supplement of chromium picolinate. British Poultry Science, v.40, n.3, p.357-363, 2001.

MERTZ, W. Chromium - history and nutritional importance. Biological Trace Element Research, v.32, p.3-8, 1992.

MOTOZONO, Y.; HATANO K.; SUGAWARA, N. et al. Effects of dietary chromium picolinate on growth, carcass quality and serum lipids of female broilers. Animal Science and Techonology (Jpn), v.69, p.659-665, 1998.

OBA, A.; SOUZA, P.A.; SOUZA, H.B.; LEONEL, F.R. et al. Qualidade da carne de frangos de corte submetidos a dietas suplementadas com crômio, criados em diferentes temperaturas ambientais. Acta Scientiarum Animal Science, v.29, n.2, p.143-149, 2007.

POLIZEL NETO, A.; JORGE, A.M.; MOREIRA, P.S. et al. Desempenho e qualidade da carne de bovinos Nelore e F1 Brangus $\mathrm{X}$ Nelore recebendo suplemento com cromo complexado à molécula orgânica na terminação a pasto. Revista Brasileira de Zootecnia, v.38, n.4, p.737-745, 2009.

PRESS, R.I.; GELLER, J.; EVANS, G.W. Effects of chromium picolinate on serum cholesterol and apopipoprotein fractions in human subjects. Western Journal of Medicine, v.152, p.41-45, 1990

ROSTAGNO, H.S.; ALBINO, L.F.T.; DONZELE, J.L. et al. Composição de alimentos e exigências nutricionais para aves e suínos (Tabelas Brasileiras). Viçosa, MG: Imp. Univ, 2005. 186p.

SANDS, J.S.; SMITH, M.O. Effects of dietary manganese proteinate or chromium picolinate supplementation on plasma insulin, glucagon, glucose and serum lipids in broiler chickens reared under thermoneutral or heat stress conditions. International Journal of Poultry Science, v.5, p.145-149, 2002 .

SILVA, D.J.; QUEIROZ, A.C. Análises de alimentos: métodos químicos e biológicos. 3.ed. Viçosa, MG: UFV, 2004. 235p.

SMITH, M.O. Parts yield of broilers reared under cycling hight temperatures. Poultry Science, v.72, p.1146-1150, 1993.

UNIVERSIDADE FEDERAL DE VIÇOSA - UFV. SAEG - Sistema de análises estatísticas e genéticas. Versão 5.0 Viçosa, MG: 1997. 150p. (Manual do usuário).

UYANIK, F.; ATASSEVER, A.; OSDAMAR, S. et al. Effects of dietary chormium chloride supplementation on performance, some serum parameters, and immune response in broilers. Biological Trace Element Research, v.90, p.99-115, 2002.

VICENT, J.B. The biochemistry of chromium. Journal Nutrition, v.130, p.715-718, 2000. 